\title{
Plasmonic Photocatalysts
}

\author{
Ewa Kowalska (D)
}

check for updates

Citation: Kowalska, E. Plasmonic Photocatalysts. Catalysts 2021, 11, 410. https://doi.org/10.3390/catal 11040410

Received: 19 March 2021 Accepted: 22 March 2021 Published: 24 March 2021

Publisher's Note: MDPI stays neutral with regard to jurisdictional claims in published maps and institutional affiliations.

Copyright: (C) 2021 by the author. Licensee MDPI, Basel, Switzerland. This article is an open access article distributed under the terms and conditions of the Creative Commons Attribution (CC BY) license (https:/ / creativecommons.org/licenses/by/ $4.0 /)$.
Institute for Catalysis (ICAT), Hokkaido University, Sapporo 001-0021, Japan; kowalska@cat.hokudai.ac.jp

Plasmonic photocatalysts, i.e., photocatalysts using plasmonic properties to gain activity under visible-light (vis) irradiation, have been intensively studied in recent years for various possible applications, including environmental purification and energy conversion. Most typical plasmonic photocatalysts are composed of wide-bandgap semiconductor, e.g., titanium (IV) oxide, and deposits of noble metals (NM). Although, NM-modified titania photocatalysts have already been extensively investigated for more than 40 years as NMs work as an electron sink inhibiting charge carriers' recombination [1-4], the use of plasmonic properties for photocatalysis could be considered as new. It is thought that the first report, proving that plasmon resonance of gold was responsible for vis response, was published by Tian and Tatsuma in 2005 [5]. Since then more and more studies have been published [6-10], and the new term of "plasmonic photocatalysis" and "plasmonic photocatalysts" have been proposed [11]. It seems that the plasmonic photocatalysis is still a "hot" topic of research on the vis-responsive materials, as observed by a high number of scientific papers published yearly (Figure 1), including highly cited and "hot" papers (46 and 3, respectively, according to Web of Science: 18 March 2021). It should be pointed out that many reports have not been even included in Figure 1, as other terms have been commonly used, e.g., "visible-light-induced photocatalysis through surface plasmon excitation of NM ... ", "gold-modified titania with vis activity", "vis response of silver-modified titanium (IV) oxide", etc. Not only research papers on plasmonic photocatalysis have been published, but also reviews and book chapters. Although, plasmonic photocatalysts have proven to be active under broad range of irradiation (UV/vis/IR) and for various applications, including wastewater and water treatment [12,13], air purification [14,15], antimicrobial materials [16-20], solar energy conversion [21,22], synthesis of organic compounds [23], and $\mathrm{CO}_{2}$ conversion [24], the activity under solar radiation (vis/NIR) is still low for broader commercialization. Therefore, various studies have been performed on activity and stability improvements of plasmonic photocatalysts, as presented in the Special Issue of Catalysts on "Plasmonic Photocatalysts".

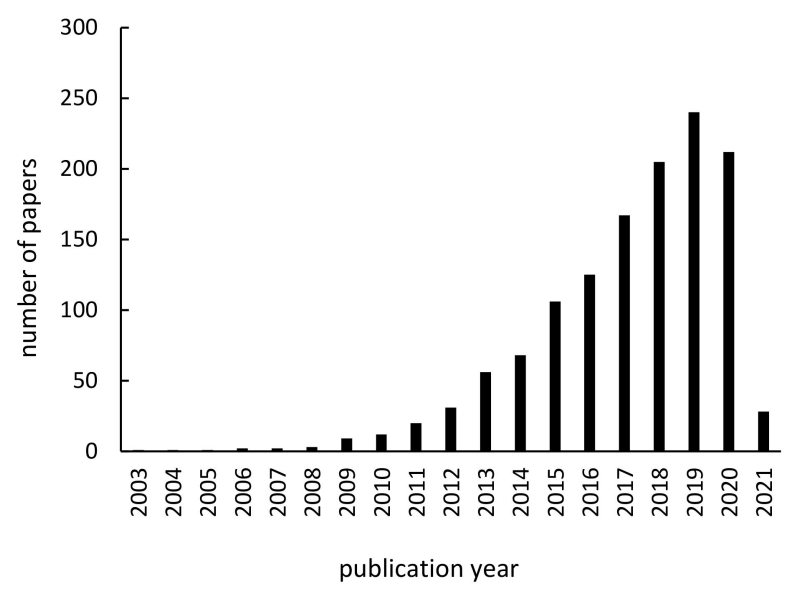

Figure 1. Number of papers published annually on plasmonic photocatalysis searched in Web of Science (18 March 2021) using "plasmon* photocatalyst" and "plasmon* catalys". 
The Special Issue is a collection of 11 papers, including three research papers and eight reviews; in total, five manuscripts have been selected as feature papers. Original papers have presented different photocatalysts, considering both semiconductor type and plasmonic metal, i.e., $\mathrm{Au}-\mathrm{Ag}$ alloy incorporated $\mathrm{AgBr}$ crystals [25], commercial titania samples modified with $\mathrm{Cu}$ deposits [26] and self-synthesized titania with defects decorated with mono- and bi-metallic $(\mathrm{Pt} / \mathrm{Cu}$ ) nanoparticles (NPs) [27]. The study by Naya et al. has shown how to efficiently form Au-Ag alloy NP of 5-nm mean size incorporated in micrometer-sized $\mathrm{AgBr}$ crystals by photochemical method [25]. It has been found that an increase in Au content in the alloy results in a drastic decrease of the local electric field enhancement (calculated by finite-difference time-domain; FDTD) and bathochromic shift of the localized surface plasmon resonance (LSPR) peak. Finally, it has been proposed that $\mathrm{Au}-\mathrm{Ag} @ \mathrm{AgBr}$ material is highly promising because of high efficiency of sunlight harvesting.

Bielan et al. have proposed defective titania modified with $\mathrm{Pt}$ and $\mathrm{Cu} \mathrm{NPs}$ of core/interlayer/shell structure with magnetic core $\left(\mathrm{Fe}_{3} \mathrm{O}_{4}\right)$ for easy separation and recycling of photocatalysts after photocatalytic reactions [27]. It has been shown that defective titania (titanium vacancies; $\mathrm{d}-\mathrm{TiO}_{2}$ ) allows efficient light harvesting, and Pt-modified d$\mathrm{TiO}_{2}$ exhibits the highest activity under vis irradiation. It should be pointed out that defects might accelerate NM aggregation due to the seed-mediated growth on the titania surface, and thus causing a decrease in metal and semiconductor interface, resulting in worsening of $\mathrm{UV} /$ vis activity. Importantly, it has been proven that the formation of $\mathrm{Fe}_{3} \mathrm{O}_{4} @ \mathrm{SiO}_{2} / \mathrm{d}-\mathrm{TiO}_{2}-$ $\mathrm{Pt} / \mathrm{Cu}$ structures allows an effective separation of the obtained magnetic photocatalysts.

The third research manuscript by Endo-Kimura et al. has discussed the modification of seven commercial titania photocatalysts of different properties (composition: anatase/rutile and particle/crystallite sizes) with Cu NPs by photo-deposition method performed in the presence or absence of methanol as a hole scavenger, i.e., during methanol dehydrogenation and water oxidation, respectively [26]. It should be underlined that though zero-valent copper has been deposited on the surface of titania (indicated by violet color of samples), copper has been oxidized in air, resulting in the co-presence of its different forms. Interestingly, the prolonged irradiation (from 1 to $5 \mathrm{~h}$ ) during preparation of samples has caused copper aggregation, and thus being detrimental for vis activity. Moreover, it has been concluded that oxidized forms of copper are more active than plasmonic one during oxidative decomposition of acetic acid under vis irradiation. Furthermore, it has been confirmed that $\mathrm{Cu} / \mathrm{TiO}_{2}$ samples show high antimicrobial effect, mainly due to the intrinsic ("dark") activity of copper species.

The review papers have presented various aspects of plasmonic photocatalysts, including nano-architecture design, experimental systems and various applications. For example, Wang et al. have discussed time-dependent measurements of tip-enhanced resonance Raman spectroscopy (TERRS) [28]. It has been shown that thermal electrons might dissociate organic compounds (Malachite Green), i.e., "plasma scissors" as an effective tool for molecular dissociation. The importance of plasmon in the field of heterogeneous photocatalysis has been underlined, such as allowing hydrogen to carry out dissociation reactions on Au NPs at room temperature. Additionally, theoretical calculations combined with real-time observations of plasmon-induced chemical reactions have been discussed, e.g., for the dissociation of S-S bonds on the surface of plasmon-induced $\mathrm{Ag}$ and $\mathrm{Cu}$.

Gong et al. have reviewed LSPR-driven photocatalytic reactions, such as dissociations of hydrogen, water, nitrogen, and carbon dioxide [29]. First, interesting introduction on the synthesis of 4,4'-dimercaptoazobenzene (DMAB) from 4-nitrobenzenethiol (4NBT) using surface-enhanced Raman scattering (SERS) technology has been presented. Then, the photosynthetic and degradation processes of 4NBT have been discussed, including the impact of various factors, such as laser wavelength, reaction time, substrate, and $\mathrm{pH}$ value. Finally, the competition between degradation and photosynthetic pathways for this reaction by SERS technology on Au-film substrate over a nanosphere has been presented. It has been concluded that plasmon-exciton interaction might increase the efficiency of chemical reactions driven by plasmonic excitation. 
A very interesting review has been prepared by Kawamura and Matsuda on the photocatalytic water splitting [30]. Although plasmonic enhancement for water splitting has been investigated broadly, the mechanisms have not been clarified and understood yet. Authors have pointed out that additionally, the yield of water splitting should be improved for commercial application. They have presented various types of plasmonic materials and semiconductors with different morphologies. The typical plasmonic materials (NM), but also other metals (e.g., $\mathrm{Al}$ ) and some transition metal nitrides, being attractive alternatives to the precious and expensive $\mathrm{Au}$ and $\mathrm{Ag}$, have been discussed in detail. Interesting aspects on the cost reduction and scale-up of plasmonic photocatalyst fabrication have also been addressed.

Huang et al. have proposed that unclarified mechanism of plasmonic photocatalysis is caused by the complexity of plasmonic optical responses and complicated microchemical processes during photocatalytic reactions [31]. Accordingly, they have presented various experimental methods used in the research on plasmonic photocatalysis and provided alternative mechanisms, based on the theoretical modeling. The five most important advantages of plasmonic effect in photocatalytic reactions have been presented, i.e., (i) efficient light harvesting, (ii) intensive light scattering, (iii) strengthening of electromagnetic field, (iv) generation of hot carriers, and (v) plasmonic heating.

The application of plasmonic photocatalysts for microbial studies have been discussed by Endo-Kimura and Kowalska [32]. It should be remembered that in the case of microorganisms, intrinsic properties of plasmonic photocatalysts (in the dark) should be considered, both for well-known antimicrobial agents as silver and copper, but also for wide-bandgap semiconductors. Accordingly, this review has presented various microbiological applications of plasmonic photocatalysis, including antibacterial, antifungal, and antiviral properties, but also a novel research on the delivery of drugs and cancer treatment. It should be pointed out that the mechanism of plasmonic photocatalysts' interactions with microorganisms has not been understood well, and contradictory data have also been published. Accordingly, the further research is necessary on the key-factor properties and the mechanisms of inactivation of microorganisms and the treatment of cancer cells.

For efficient light harvesting the application of photonic crystals (PC) as a support for NMs have been discussed by Raja-Mogan et al. [33]. It is important to mention that though PCs might possess vis response due to photonic bandgap (PBG) and slow photon effects at vis/IR range of solar spectrum, it should not result in vis-activity of wide-bandgap semiconductors. In contrast, PCs-based plasmonic photocatalysts are promising candidates for high photocatalytic performance, as proven in discussed papers. However, it should be pointed out that the synthesis of both PCs and PCs-based plasmonic photocatalysts is challenging, involving multi-step procedures, and also the preservation of PC structure during activity testing must be ensured (not to lose photonic properties). It has been concluded that the best method to obtain highly active photocatalyst is to tune the photo-absorption properties, i.e., to match the PBG edge (slow photon effect) with LSPR wavelengths by the change in the void diameter of inverse opal PC and the size of NMNPs, respectively.

Similarly, the reviews by Wei et al. [34] and Garcia-Peiro et al. [35] have underlined the importance of the morphology. For example, faceted nanoparticles, aerogels, nanowires, nanotubes, and super-nano structures of semiconductors have shown enhanced photocatalytic activity and high stability [34]. Additionally, NM deposition on special parts of supports, such as facets, might accelerate the activity. It should be pointed out the though bi-, and ternary-metal-modifications have been suggested for enhanced light harvesting, the co-interactions between NMs have also caused a decrease in activity. Interestingly, the difficulties in photocatalysts comparison have been pointed out, as different irradiation sources, photoreactors, tested compounds, and reaction conditions are commonly used, and quantum yields have been estimated only in several studies. Another problem is connected with the use of solar radiation or solar simulators (also containing UV), and thus excitation of semiconductor should be rather considered than plasmonic photocatalysis. Additionally, during mechanism study the activity tests should not be performed for dye 
discoloration, as photocatalyst sensitization by dye might be the predominant mechanism of their degradation rather than vis-activity caused by plasmonic photocatalysts.

Interesting review has been prepared by Garcia-Peiro et al. since they have looked for an alternative to famous titania to obtain photocatalysts of better performance [35]. They have discussed the correlation between the morphology and photocatalytic activities of gold-modified non-titania-based semiconductors, including $\mathrm{Au}-\mathrm{CeO}_{2}, \mathrm{Au}-\mathrm{Cu}_{2} \mathrm{O} / \mathrm{Au}$ $\mathrm{CuS}$, and Au-CdS. It has been confirmed that the morphology is key-factor of activity, and that the less-conventional design might result in breakthroughs in plasmonic photocatalysis. Furthermore, the anisotropic metals are highly attractive for efficient light harvesting. They have also emphasized the need to establish the control and clear definition of hetero-nanoarchitectures at the nanoscale level for fast progress in research, especially for biomedical applications.

It is obvious that excellent research has been performed worldwide on plasmonic photocatalysts for various types of materials, reactions systems, and applications. It might be concluded that plasmonic photocatalysis is a very active field of research, with promising results for future commercialization. On the other hand, further research is highly needed, especially to clarify the mechanism, standardization of research practices and to find the key-factors of photocatalytic activity.

Finally: I would like to thank all authors for their valuable contributions, without which this special issue would not have been possible. I would like to express my sincerest thanks to the editorial team of Catalysts (especially Ms. Janine Li) for their kind support, advices, and fast responses.

Conflicts of Interest: The author declares no conflict of interest.

\section{References}

1. Kraeutler, B.; Bard, A.J. Heterogeneous photocatalytic preparation of supported catalysts. Photodeposition of platinum on $\mathrm{TiO}_{2}$ powder and other substrates. J. Am. Chem. Soc. 1978, 100, 4317-4318. [CrossRef]

2. Ohtani, B.; Kakimoto, M.; Nishimoto, S.; Kagiya, T. Photocatalytic reaction of neat alcohols by metal-loaded titanium(IV) oxide particles. J. Phys. Chem. A Chem. 1993, 70, 265-272. [CrossRef]

3. Herrmann, J.-M.; Disdier, J.; Pichat, P. Photoassisted platinum deposition on $\mathrm{TiO}_{2}$ powder using various platinum complexes. J. Phys. Chem. 1986, 90, 6028-6034. [CrossRef]

4. Kowalska, E.; Remita, H.; Colbeau-Justin, C.; Hupka, J.; Belloni, J. Modification of titanium dioxide with platinum ions and clusters: Application in photocatalysis. J. Phys. Chem. C 2008, 112, 1124-1131. [CrossRef]

5. Tian, Y.; Tatsuma, T. Mechanisms and Applications of Plasmon-Induced Charge Separation at $\mathrm{TiO}_{2}$ Films Loaded with Gold Nanoparticles. J. Am. Chem. Soc. 2005, 127, 7632-7637. [CrossRef] [PubMed]

6. Kowalska, E.; Abe, R.; Ohtani, B. Visible light-induced photocatalytic reaction of gold-modified titanium(IV) oxide particles: Action spectrum analysis. Chem. Commun. 2009, 241-243. [CrossRef] [PubMed]

7. Kominami, H.; Tanaka, A.; Hashimoto, K. Mineralization of organic acids in aqueous suspension of gold nanoparticles supported on cerium(IV) oxide powder under visible light irradiation. Chem. Commun. 2010, 46, 1287-1289. [CrossRef] [PubMed]

8. Verbruggen, S.W.; Keulemans, M.; Goris, B.; Blommaerts, N.; Bals, S.; Martens, J.A.; Lenaerts, S. Plasmonic 'rainbow' photocatalyst with broadband solar light response for environmental applications. Appl. Catal. B Environ. 2016, 188, 147-153. [CrossRef]

9. Mukherjee, S.; Libisch, F.; Large, N.; Neumann, O.; Brown, L.V.; Cheng, J.; Lassiter, J.B.; Carter, E.A.; Nordlander, P.; Halas, N.J. Hot Electrons Do the Impossible: Plasmon-Induced Dissociation of $\mathrm{H}_{2}$ on Au. Nano Lett. 2013, 13, 240-247. [CrossRef]

10. Mizeikis, V.; Kowalska, E.; Juodkazis, S. Resonant, localization, enhancement, and polarization o optical fields in nano-scale interface regions for photo-catalytic application. J. Nanosci. Nanotechnol. 2011, 11, 2814-2822. [CrossRef] [PubMed]

11. Awazu, K.; Fujimaki, M.; Rockstuhl, C.; Tominaga, J.; Murakami, H.; Ohki, Y.; Yoshida, N.; Watanabe, T. A plasmonic photocatalyst consisting of sliver nanoparticles embedded in titanium dioxide. J. Am. Chem. Soc. 2008, 130, 1676-1680. [CrossRef]

12. Kowalska, E.; Janczarek, M.; Rosa, L.; Juodkazi, S.; Ohtani, B. Mono- and bi-metallic plasmonic photocatalysts for degradation of organic compounds under UV and visible light irradiation. Catal. Today 2014, 230, 131-137. [CrossRef]

13. Wang, X.P.; Tang, Y.X.; Chen, Z.; Lim, T.T. Highly stable heterostructured Ag- $\mathrm{AgBr} / \mathrm{TiO}_{2}$ composite: A bifunctional visible-light active photocatalyst for destruction of ibuprofen and bacteria. J. Mater. Chem. 2012, 22, 23149-23158. [CrossRef]

14. Wysocka, I.; Markowska-Szczupak, A.; Szweda, P.; Ryl, J.; Endo-Kimura, M.; Kowalska, E.; Nowaczyk, G.; Zielinska-Jurek, A. Gas-phase removal of indoor volatile organic compounds and airborne microorganisms over mono- and bimetal-modified (Pt, $\mathrm{Cu}, \mathrm{Ag}$ ) titanium(IV) oxide nanocomposites. Indoor Air 2019, 29, 979-992. [CrossRef] [PubMed]

15. Verbruggen, S.W. $\mathrm{TiO}_{2}$ photocatalysis for the degradation of pollutants in gas phase: From morphological design to plasmonic enhancement. J. Photoch. Photobio. C 2015, 24, 64-82. [CrossRef] 
16. Rtimi, S.; Baghriche, O.; Sanjines, R.; Pulgarin, C.; Bensimon, M.; Kiwi, J. TiON and TiON-Ag sputtered surfaces leading to bacterial inactivation under indoor actinic light. J. Photoch. Photobio. A 2013, 256, 52-63. [CrossRef]

17. Endo, M.; Janczarek, M.; Wei, Z.; Wang, K.; Markowska-Szczupak, A.; Ohtani, B.; Kowalska, E. Bactericidal properties of plasmonic photocatalysts composed of noble-metal nanoparticles on faceted ana-tase titania. J. Nanosci. Nanotechnol. 2019, 19, 442-452. [CrossRef] [PubMed]

18. Endo, M.; Wei, Z.S.; Wang, K.L.; Karabiyik, B.; Yoshiiri, K.; Rokicka, P.; Ohtani, B.; Markowska-Szczupak, A.; Kowalska, E. Noble metal-modified titania with visible-light activity for the decomposition of microorganisms. Beilstein J. Nanotech. 2018, 9, 829-841. [CrossRef]

19. Wei, Z.; Endo, M.; Wang, K.; Charbit, E.; Markowska-Szczupak, A.; Ohtani, B.; Kowalska, E. Noble metal-modified octahedral anatase titania particles with enhanced activity for decomposition of chemical and microbiological pollutants. Chem. Eng. J. 2017, 318, 121-134. [CrossRef] [PubMed]

20. Kowalska, E.; Wei, Z.; Karabiyik, B.; Herissan, A.; Janczarek, M.; Endo, M.; Markowska-Szczupak, A.; Remita, H.; Ohtani, B. Silver-modified titania with enhanced photocatalytic and antimicrobial properties under UV and visible light irradiation. Catal. Today 2015, 252, 136-142. [CrossRef]

21. Solarska, R.; Bienkowski, K.; Zoladek, S.; Majcher, A.; Stefaniuk, T.; Kulesza, P.J.; Augustynski, J. Enhanced Water Splitting at Thin Film Tungsten Trioxide Photoanodes Bearing Plasmonic Gold-Polyoxometalate Particles. Angew. Chem. Int. Ed. 2014, 53, 14196-14200. [CrossRef] [PubMed]

22. Warren, S.C.; Thimsen, E. Plasmonic solar water splitting. Energy Environ. Sci. 2012, 5, 5133-5146. [CrossRef]

23. Wang, C.L.; Astruc, D. Nanogold plasmonic photocatalysis for organic synthesis and clean energy conversion. Chem. Soc. Rev. 2014, 43, 7188-7216. [CrossRef] [PubMed]

24. Wang, C.J.; Ranasingha, O.; Natesakhawat, S.; Ohodnicki, P.R.; Andio, M.; Lewis, J.P.; Matranga, C. Visible light plasmonic heating of $\mathrm{Au}-\mathrm{ZnO}$ for the catalytic reduction of $\mathrm{CO}_{2}$. Nanoscale 2013, 5, 6968-6974. [CrossRef]

25. Naya, S.-I.; Fujishima, M.; Tada, H. Synthesis of Au-Ag Alloy Nanoparticle-Incorporated AgBr. Crystals 2019, 9, 745. [CrossRef]

26. Endo-Kimura, M.; Karabiyik, B.; Wang, K.; Wei, Z.; Ohtani, B.; Markowska-Szczupak, A.; Kowalska, E. Vis-responsive coppermodified titania for decomposition of organic compounds and microorganisms. Crystals 2020, 10, 1194. [CrossRef]

27. Bielan, Z.; Sulowska, A.; Dudziak, S.; Siuzdak, K.; Ryl, J.; Zielinska-Jurek, A. Defective $\mathrm{TiO}_{2}$ core-shell magnetic photocatalyst modified with plasmonic nanoparticles for visible light-induced photocatalytic activity. Catalysts 2020, 10, 672. [CrossRef]

28. Wang, J.; Wang, X.; Mu, X. Plasmonic Photocatalysts Monitored by Tip-Enhanced Raman Spectroscopy. Catalysts 2019, 9, 109. [CrossRef]

29. Gong, Z.; Ji, J.; Wang, J. Photocatalytic Reversible Reactions Driven by Localized Surface Plasmon Resonance. Catalysts 2019, 9 , 193. [CrossRef]

30. Kawamura, G.; Matsuda, A. Synthesis of Plasmonic Photocatalysts for Water Splitting. Catalysts 2019, 9, 982. [CrossRef]

31. Huang, H.J.; Wu, J.C.-S.; Chiang, H.-P.; Chou Chau, Y.-F.; Lin, Y.-S.; Wang, Y.H.; Chen, P.-J. Review of Experimental Setups for Plasmonic Photocatalytic Reactions. Catalysts 2020, 10, 46. [CrossRef]

32. Endo-Kimura, M.; Kowalska, E. Plasmonic Photocatalysts for Microbiological Applications. Catalysts 2020, 10, 824. [CrossRef]

33. Raja-Mogan, T.; Ohtani, B.; Kowalska, E. Photonic crystals for plasmonic photocatalysis. Catalysts 2020, 10, 827. [CrossRef]

34. Wei, Z.; Janczarek, M.; Wang, K.; Zheng, S.; Kowalska, E. Morphology-governed performance of plasmonic photocatalysts. Catalysts 2020, 10, 1070. [CrossRef]

35. Garcia-Peiro, J.I.; Bonet-Aleta, J.; Bueno-Alejo, C.J.; Hueso, J.L. Recent Advances in the Design and Photocatalytic Enhanced Performance of Gold Plasmonic Nanostructures Decorated with Non-Titania Based Semiconductor Hetero-Nanoarchitectures. Catalysts 2020, 10, 1459. [CrossRef] 